\title{
Insight into the Mode of Action of Haedoxan A from Phryma leptostachya
}

\author{
Zhaonong $\mathrm{Hu}{ }^{1,2,+}$, Yuzhe Du ${ }^{3,+}$, Xinmin Xiao ${ }^{1}$, Ke Dong ${ }^{3}$ and Wenjun $\mathrm{Wu}^{1,2, *}$ \\ 1 Institute of Pesticide Science, College of Plant Protection, Northwest A \& F University, Yangling 712100, \\ Shaanxi, China; huzhaonong@nwsuaf.edu.cn (Z.H.); xiaoxinmin@126.com (X.X.) \\ 2 Key Laboratory of Botanical Pesticide R \& D in Shaanxi Province, Yangling 712100, Shaanxi, China \\ 3 Department of Entomology, Michigan State University, East Lansing, MI 48824, USA; duy@msu.edu (Y.D.); \\ dongk@msu.edu (K.D.) \\ * Correspondence: wuwenjun@nwsuaf.edu.cn; Tel.: +86-29-8709-3987; Fax: +86-29-8709-2191 \\ + These two authors contribute equally to this work.
}

Academic Editor: Tzi Bun NG

Received: 12 December 2015; Accepted: 15 February 2016; Published: 22 February 2016

\begin{abstract}
Haedoxan A (HA) is a major active ingredient in the herbaceous perennial plant lopseed (Phryma leptostachya L.), which is used as a natural insecticide against insect pests in East Asia. Here, we report that HA delayed the decay rate of evoked excitatory junctional potentials (EJPs) and increased the frequency of miniature EJPs (mEJPs) on the Drosophila neuromuscular junction. HA also caused a significant hyperpolarizing shift of the voltage dependence of fast inactivation of insect sodium channels expressed in Xenopus oocytes. Our results suggest that HA acts on both axonal conduction and synaptic transmission, which can serve as a basis for elucidating the mode of action of HA for further designing and developing new effective insecticides.
\end{abstract}

Keywords: botanical insecticides; haedoxan A (HA); synaptic transmission; voltage-gated sodium channel

\section{Introduction}

The herbaceous perennial plant lopseed Phryma leptostachya L., the sole species of the family Phrymaceae, is widely distributed in the Himalayas, temperate Asia, and northern East America and is traditionally used as a natural insecticide in East Asia [1,2]. Since the 1960s, Taniguchi et al. [3-5] have isolated a series of Phryma lignans with 3,7-dioxabicyclo [3.3.0] octane skeleton, such as phrymarolin I, phrymarolin II, and haedoxan A (HA). Interestingly, HA is the sole ingredient with higher insecticidal activity against the housefly compared with commercial synthetic pyrethroids [5]. Subsequently, the synthesis and structure-activity relationships of HA were examined [6,7]. Phrymarolin I and II belong to a class of dilignans deprived of the 3-phenyl-2-hydroxymethyl-1, 4-benzodioxane framework of haedoxans and are totally inactive [8-12]. However, leptostachyol acetate, whose chemical structure is very similar to those of phrymarolin-I and II, is active against larvae of three different mosquito species [13] and housefly [14].

Our laboratory has systemically isolated the insecticidal ingredients of $P$. leptostachya and investigated its insecticidal activities in recent years [15-17]. Encouraged by the larvicidal activities against mosquitoes, four high mosquiticidal compounds were isolated, including phrymarolin I, HA, haedoxan E, and a new compound named phrymarolin B, the structure of which was elucidated as 1-hydroxy-2-( $3^{\prime}, 4^{\prime}$-methylenedioxy) phenoxy-6-( $2^{\prime \prime}$-hydroxy- $3^{\prime \prime}, 4^{\prime \prime}$-methylenedioxy) phenyl-3,7-dioxabicyclo[3.3.0]octane [17]. The $\mathrm{LC}_{50}$ values of four insecticidal compounds against the fourth-instar larvae of Culex pipiens pallen were 1.21, 0.025, 0.15, and $0.69 \mathrm{mg} / \mathrm{L}$, respectively. 
HA, haedoxan E, and phrymarolin B also have significant contact and stomach toxicities against the third-instar larvae of the oriental armyworm Mythimna separata. These results further illustrate that HA is the most potential insecticidal ingredient of $P$. leptostachya. Hence, developing a novel natural botanical pesticide based on $\mathrm{HA}$ as a major insecticidal active ingredient is promising.

Regarding the mode of action of HA, early studies have shown that when HA is ingested by larvae of some species of lepidopterous insects, HA causes early cessation of feeding, muscle relaxation and, ultimately, death, of tested insects [5]. According to the poisoning symptoms of treated insects and high stereoselectivity required for their insecticidal activities, HA may act on receptors in neurons or muscle $[5,18]$. Insecticidal (+)-HA and three other noninsecticidal isomers can inhibit [ $\left.{ }^{35} \mathrm{~S}\right]$ t-butylbicyclophosphorothionate(TBPS) binding on the GABA receptor allosterically in a concentration-dependent manner by coupled interaction with the TBPS-binding site in rat brain, which is distinct from the GABA-binding site. Apparently, the lethal activity of (+)-HA against insects is not due to the action at the $\mathrm{GABA}_{\mathrm{A}}$ receptor, although it may contribute to the initial excitation, as observed in the injection of haedoxan isomers into German cockroaches [18]. Therefore, the mode of action of HA remains unknown.

In the present study, we investigated the effects of HA on excitatory transmission at the Drosophila neuromuscular junction (NMJ) and on voltage-gated insect sodium channels expressed in Xenopus oocytes. Results showed that HA delayed the decay rate of excitatory junctional potentials (EJPs) and, increased the frequency of miniature EJPs (mEJPs) on Drosophila NMJ, and altered the voltage dependence of sodium channel inactivation. These findings revealed potential targets of action of HA and laid a foundation for further elucidation of the molecular mechanisms of action of this botanical insecticide.

\section{Results}

\subsection{HA Delayed the Decay Rate of Evoked EJPs at the Drosophila NMJ}

HA causes muscle relaxation in houseflies [5,16], so we chose the Drosophila NMJ [19,20] to examine the effect of HA on synaptic transmission using intracellular recording. Before HA treatment in HL3 solution (containing $1.5 \mathrm{mM} \mathrm{Ca}^{2+}$ ), the peak amplitude of evoked EJPs was $34.32 \pm 5.03 \mathrm{mV}$. In the absence of $\mathrm{HA}$, the amplitude of evoked EJPs was gradually reduced in response to $0.1 \mathrm{~Hz}$ stimulation for $60 \mathrm{~min}$ (Figure 1A,C) from 94\% of the initial amplitude at $10 \mathrm{~min}$ to $91 \%, 83 \%$ and $77 \%$ of the initial amplitude at 20,40, and $60 \mathrm{~min}$, respectively. Three minutes after HA application (final concentration $=2.5 \times 10^{-6} \mathrm{M}$ ), the amplitude of evoked EJPs remained similar to that before HA treatment (Figure 1A,B). However, application of HA at $2.5 \times 10^{-6} \mathrm{M}$ did not cause significant decreases in the evoked EJPs amplitude from $10 \mathrm{~min}$ to $60 \mathrm{~min}$ of $0.1 \mathrm{~Hz}$ stimulation (Figure 1C). These results indicated that HA was able to maintain the evoked EJPs in response to sustained low-frequency stimulations.

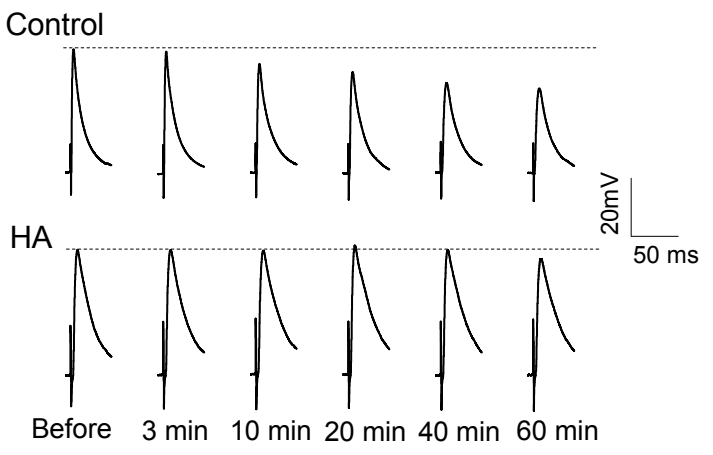

A

Figure 1. Cont. 


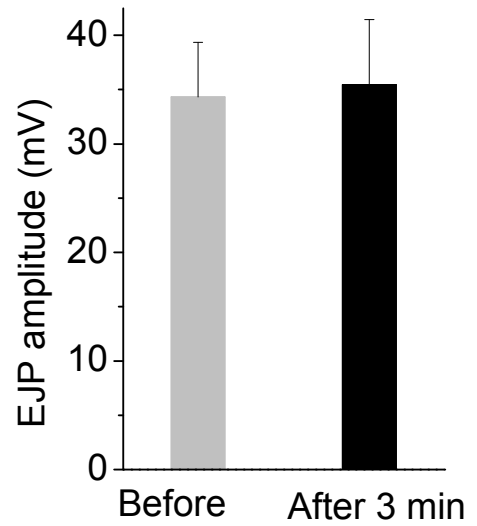

B

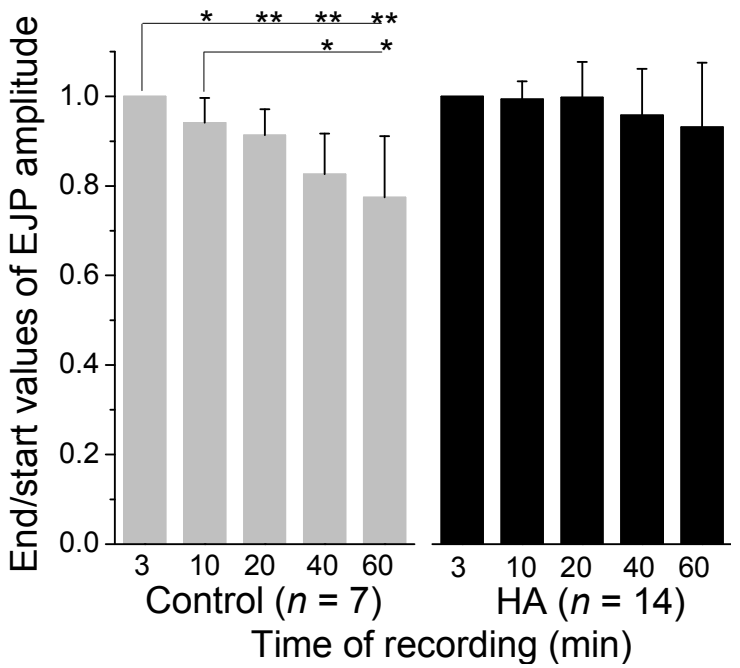

C

Figure 1. HA delayed the decay rate of the evoked EJPs at the Drosophila neuromuscular junction. (A) representative EJPs traces in control and in the presence of HA $\left(2.5 \times 10^{-6} \mathrm{M}\right)$. (B) mean amplitude of evoked EJPs before and after $3 \mathrm{~min}$ of HA application. Evoked EJPs were elicited by stimulating the segmental nerve at $0.1 \mathrm{~Hz}$ with the amplitude of the pulse of $5 \mathrm{~V}$. The values reported are the mean \pm SD. (C) mean amplitude of evoked EJPs at various time points (3, 10, 20, 40, and $60 \mathrm{~min})$ in control and in the presence of HA were normalized to the initial amplitude of evoked EJPs, i.e., $n=7$ for the control and $n=14$ for HA treated. Statistical significance was determined by Student's $t$-test, and significant values were set at ${ }^{*} p<0.05$ and ${ }^{* *} p<0.01$.

\subsection{HA Increased the Frequency of $m E J P s$ at the Drosophila NMJ}

In our recording from the NMJ of $w^{1118}$ flies, the average values of the resting membrane potential was $70.9 \pm 1.7 \mathrm{mV}(n=50$, mean $\pm \mathrm{SE})$. In this resting condition, $\mathrm{mEJPs}$ can be recorded. Each $\mathrm{mEJP}$ represented postsynaptic depolarization in response to the spontaneous fusion of a single synaptic vesicle $[21,22]$.

At $0.1 \mathrm{~Hz}$ nerve stimulation, the representative of mEJP traces in control and in the presence of HA are shown in Figure 2A. The release rate of mEJPs finally increased after HA application, but that of the control decayed with time (Figure 2A-I). We also recorded the overlap and summation of mEJPs recorded after 20 min by HA application, which occurred in about $33 \%$ of the total recordings (Figure 2A-I). By box plots of mEJP amplitudes (Figure 2B-I), we noted that the median mEJP amplitude dropped slowly with time in the control, whereas the decrease in HA amplitude was similar to that of the control over 10 and $20 \mathrm{~min}$. Subsequently, the median mEJPs amplitude increased at 40 and $60 \mathrm{~min}$, which were higher than the initial baseline amplitude 3 min after HA application. In the absence of HA, the average amplitude of mEJPs recorded slightly decreased over the first 3 min (Figure 2B-III). Similar to that of the control, the average amplitude of mEJPs in the presence of HA also decreased over 10 and $20 \mathrm{~min}$. Overall, no significant difference was observed with time for mean mEJP amplitudes on both with and without HA application (Figure 2B-II and 2B-III; $p>0.05$ ). By contrast, a significant enhancement in the frequency of spontaneous miniature events at mEJPs was induced by HA (final concentration $=2.5 \times 10^{-6} \mathrm{M}$ ). In the absence of $\mathrm{HA}$, the release rate of mEJPs decreased with time. mEJP frequency dropped from $80 \%$ of the initial frequency at $10 \mathrm{~min}$ to $44 \%$ at $60 \mathrm{~min}$ (Figure 2C-I and 2C-II). Compared with the time-dependent drop of mEJP frequency in the control, the mEJP frequency in HA dropped to $0.852 \pm 0.117$ of initial frequency at $10 \mathrm{~min}(p<0.05, n=9)$ as same as that of the control, and then increased relatively to $0.878 \pm 0.179$ of initial frequency at $20 \mathrm{~min}(p>0.05)$. Subsequently, the mEJPs frequency increased significantly to $1.444 \pm 0.713$ and $1.271 \pm 0.451$ of the initial frequency at 40 and $60 \mathrm{~min}(p<0.01)$, respectively. Furthermore, HA can also produce some 
irregular mEJPs increments over $20 \mathrm{~min}$, in which the mEJP rate could not be counted in most cases due to the overlap and summation of potentials (Figure 2A-II). However, the increase was usually sudden and obvious, making quantitation impossible and unnecessary. The significant enhancement in the frequency of mEJPs induced by HA indicated that HA may produce a relatively high rate of spontaneous synaptic vesicle fusion events at motor terminals.
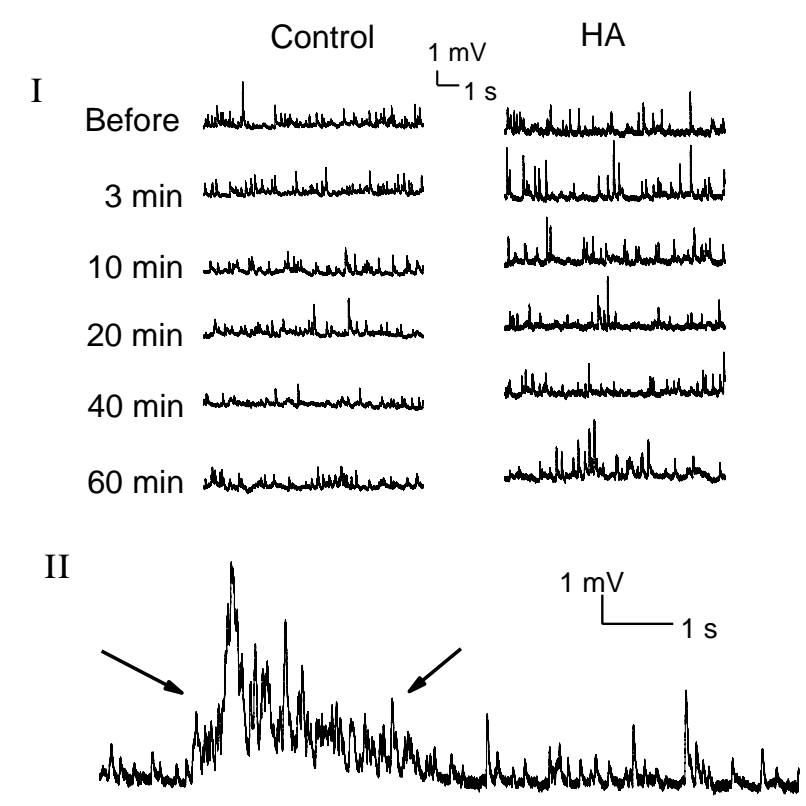

(A)

I

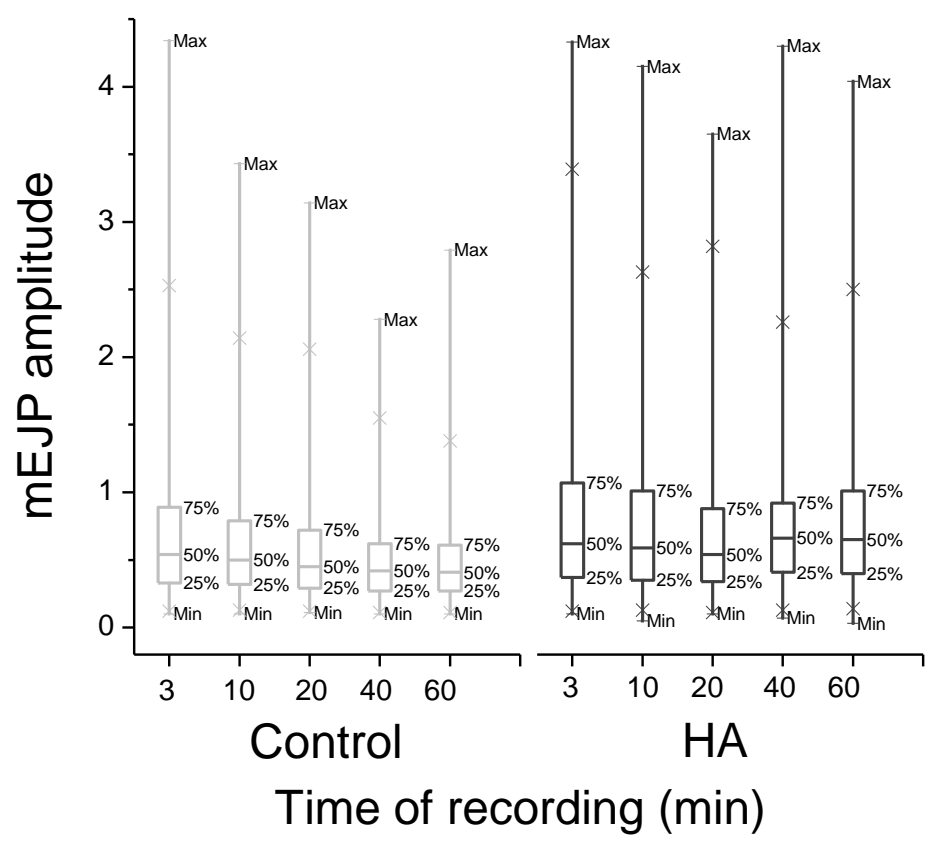

Figure 2. Cont. 
II

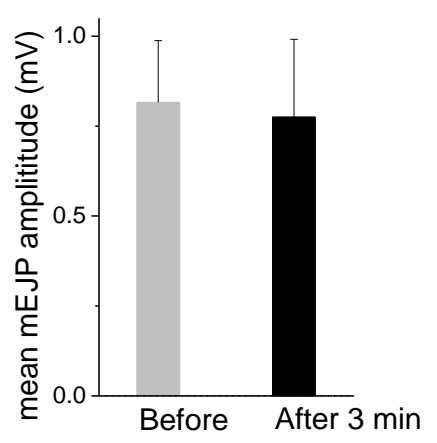

I

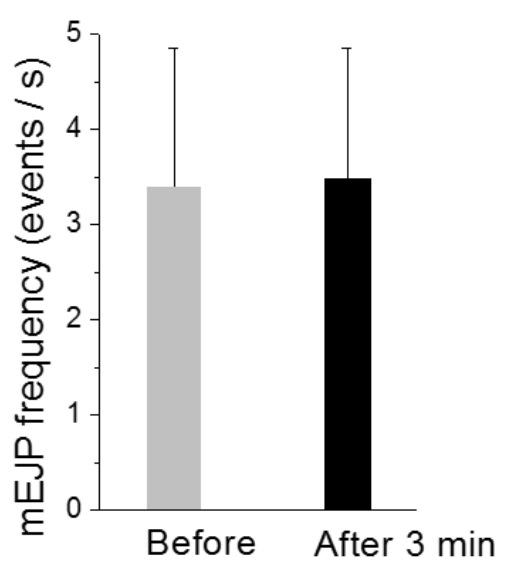

III

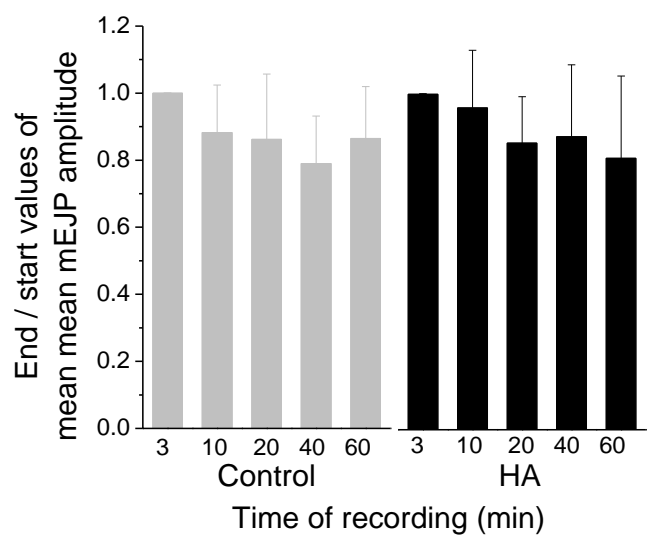

(B)

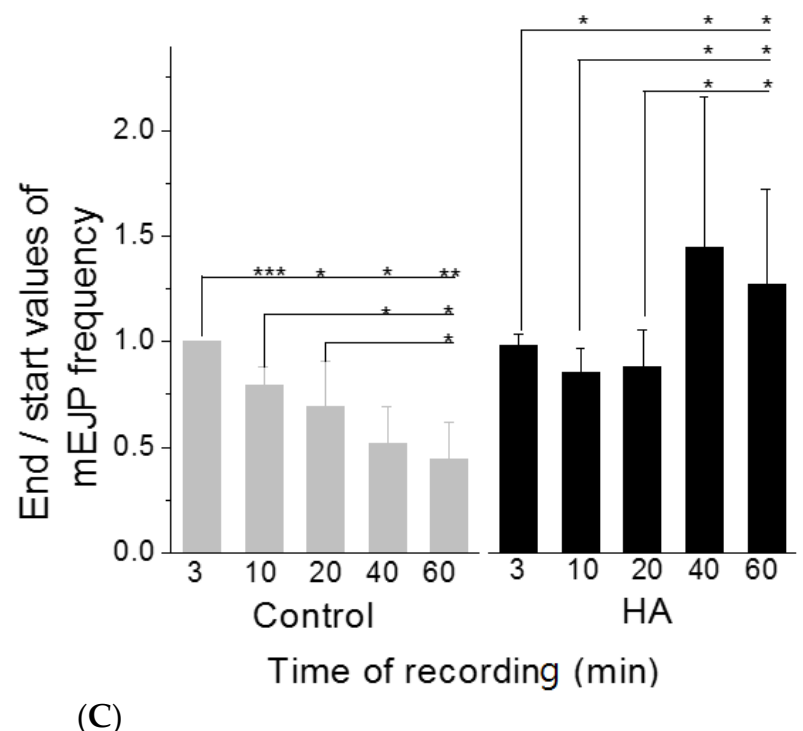

Figure 2. HA increased the frequency of mEJPs at the Drosophila neuromuscular junction. (A) I, representative of mEJP traces in the control and in the presence of HA $\left(2.5 \times 10^{-6} \mathrm{M}\right)$. II, overlap and summation of mEJPs recorded $20 \mathrm{~min}$ after HA application, which occurred in about $33 \%$ of total recordings. Arrows indicate the irregular mEJPs. (B) analysis of mEJP amplitudes; HA did not affect the average amplitude of mEJPs. I, box plots of mEJPs amplitudes. II, mEJPs amplitude before and at 3 min after HA application showing no significant difference; III, mean mEJPs amplitude at different time points $(3,10,20,40$, and $60 \mathrm{~min})$ in the control and HA application were normalized to the initial mEJPs amplitude in the control and HA application, separately. No significant difference was observed with time on mEJPs amplitude in both control and HA application $(p>0.05)$. (C) analysis of mJPs frequencies, HA induced a significant enhancement in the frequency of mEJPs. I, mEJP frequency before and after $3 \mathrm{~min}$ of HA application; there is no significant difference ( $p>0.05)$; II, mEJP frequency at different time points $(3,10,20,40$, and $60 \mathrm{~min})$ in the control and HA application were normalized to the initial mEJP frequency in the control and HA application, separately. mEJP frequency in the control showing significant decrease with time, whereas HA induced a significant increase at 40 and $60 \mathrm{~min}$. Notably, the start and end values of mEJPs amplitude/or frequency in (C) are the EJP amplitude/or frequency at $3 \mathrm{~min}$ after application and other different recording times, respectively. The values reported in (C) are the mean $\pm \mathrm{SD}$. HA, $n=7$; control $n=6$. Statistical significance was determined by Student's $t$-test, and significant values were set at ${ }^{*} p<0.05$ and ${ }^{* *} p<0.01,{ }^{* * *} p<0.001$. 


\subsection{HA Altered the Voltage Dependence of Inactivation of Insect Sodium Channels Expressed in Xenopus oocytes}

A motoneuron carrying the impulse creates synapses with the muscle fiber, which is known as NMJs [23]. The muscle infolds participating in the synapse contains a large number of sodium channels [23]. Voltage-gated sodium channels (VGSCs) are known to play a central role in action potential generation and propagation in nerve and muscle [24]. In skeletal muscles, VGSCs are concentrated at NMJs in the depths of the postsynaptic folds [25-27]. The sodium current that passes through the narrow synaptic cleft affects the adjacent membranes electrical properties and in turn modifies synaptic transmission process. Hence, determining whether HA affected VGSCs was very interesting. In a previous experiment, we investigated the effects of HA on excitatory transmission at the Drosophila NMJ. German cockroach have been injected with haedoxan isomers to induce muscle relaxation [18], and mosquito Culex pipiens pallen have been chosen for bioassay. In the present work, three insect sodium channels, namely, cockroach $\mathrm{BgNa}_{\mathrm{v}} 1-1 \mathrm{a}$, fruit fly $\mathrm{DmNa}_{\mathrm{v}} 22$, and mosquito $\mathrm{AaNa}_{\mathrm{v}} 1-1 \mathrm{a}$ sodium channels, were examined for the effects of HA on VGSCs.

Cockroach $\mathrm{BgNa}_{\mathrm{v}} 1-1 \mathrm{a}$, Drosophila $\mathrm{DmNa}_{\mathrm{v}} 22$, and mosquito $\mathrm{AaNa}_{\mathrm{v}} 1-1 \mathrm{a}$ sodium channels were expressed in Xenopus oocytes, and the gating properties of these channels were examined with two electrode-voltage clamp. HA did not alter the amplitude of sodium currents or the voltage dependence of activation or activation kinetics of sodium channels (Table 1 and Figure 3). However, HA $\left(10^{-5} \mathrm{M}\right)$ shifted the voltage dependence of inactivation of all three insect sodium channels by 8-11 $\mathrm{mV}$ in the hyperpolarizing direction (Table 1 and Figure 3).
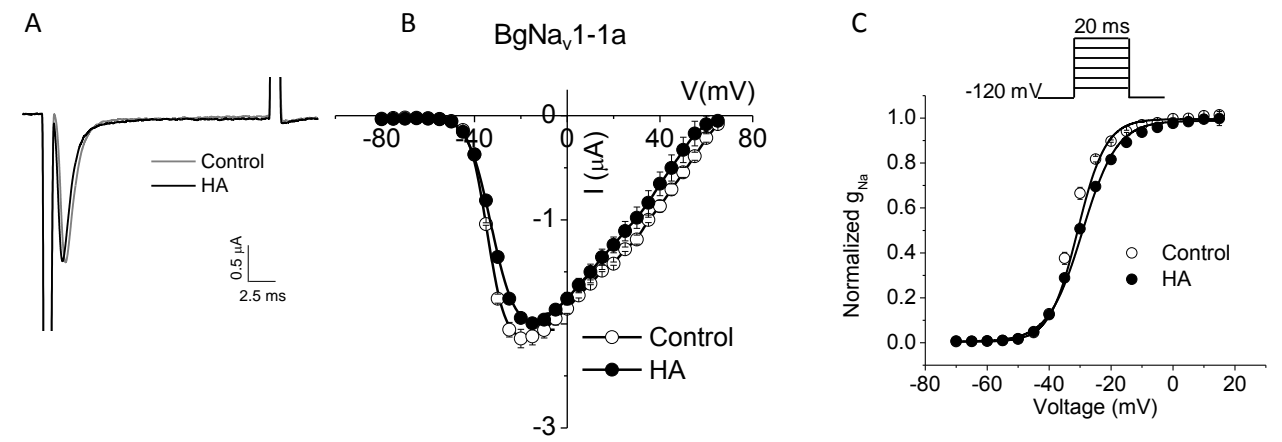

D

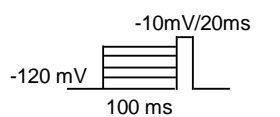

E

F
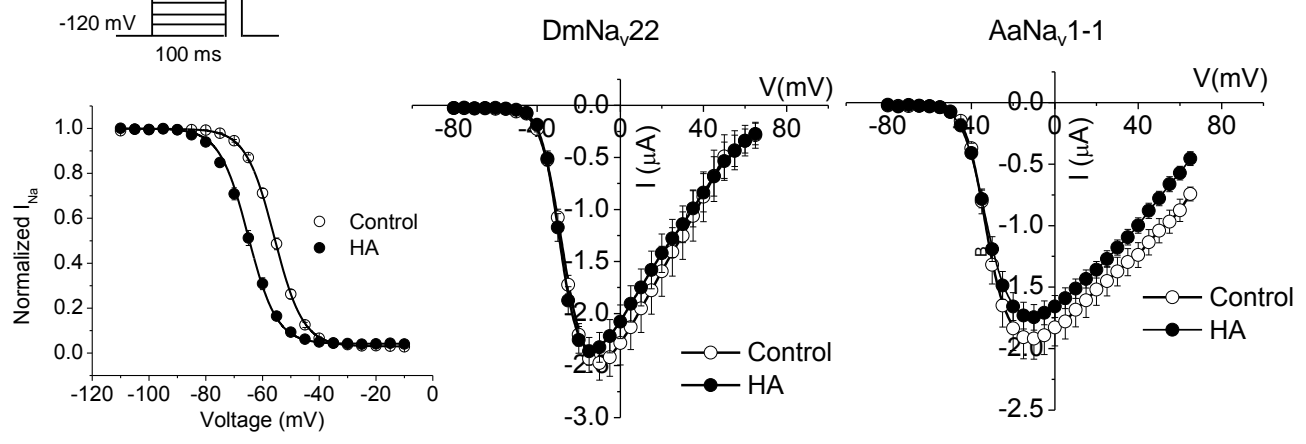

Figure 3. HA induced a significant hyperpolarization direction shift in inactivation-gating properties in cockroach sodium channels BgNav1-1a. (A) recording traces before and after the application of $10^{-5} \mathrm{M}$ of HA; (B) I-V curve of cockroach sodium channels BgNav1-1a before and after the application of $10^{-5} \mathrm{M}$ of HA; (C) and (D) the voltage dependence of activation (C) and inactivation (D) before and after the application of $10^{-5} \mathrm{M}$ of HA. The activation and inactivation curves were fitted with two-state Boltzmann equations. The number of oocytes was 5-8; (E) and (F) I-V curve of Drosophila sodium channels $\mathrm{DmNa}_{\mathrm{v}} 22(\mathrm{E})$ and mosquito sodium channels $\mathrm{AaNa}_{\mathrm{v}} 1-1(\mathbf{F})$ before and after the application of $10^{-5} \mathrm{M}$ of $\mathrm{HA}$. 
Table 1. Voltage dependence of activation and inactivation of four sodium channels before and after the application of HA.

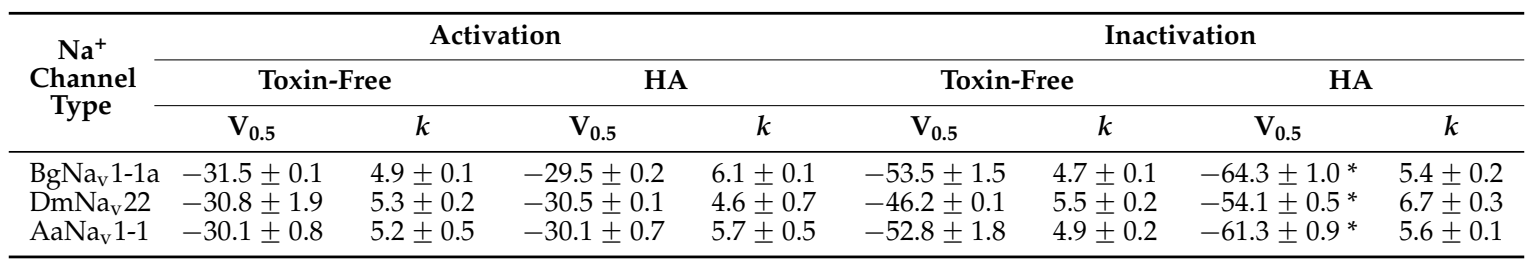

Results are the mean \pm SD for 5-8 oocytes. Asterisks indicate significant differences from toxin free as determined by one-way ANOVA $(p<0.05)$ with Scheffe's post hoc analysis.

\section{Discussion}

In this study, we investigated the effects of HA on excitatory transmission at the Drosophila NMJ and voltage-gated insect sodium channels expressed in Xenopus oocytes. The mode of action of HA is studied at the molecular level for the first time. We observed that HA delayed the decay rate of evoked EJPs and increased the frequency of mEJPs on the Drosophila NMJ at least to 1.27- to 1.44-fold of initial frequency. We also found that HA caused a significant hyperpolarizing shift of the voltage dependence of fast inactivation of insect sodium channels by $8-10 \mathrm{mV}$. These findings meant that HA may acts on both axonal conduction and synaptic transmission. Interestingly, linking the physiological changes induced by HA in the nerve endings with its ability to modify the $\mathrm{Na}^{+}$channels was essential.

The motoneuron connects to the muscle fiber at NMJs to ensure a rapid and efficient transmission of the impulse. At the presynaptic nerve terminal, the voltage-dependent calcium channels opens up increasing the $\mathrm{Ca}^{2+}$ ions permeability which allows $\mathrm{Ca}^{2+}$ to flow in. This causes the vesicles to be fused with the presynaptic membrane and release neurotransmitter at the synaptic cleft. The neurotransmitter diffuses at the cleft and binds with the relative neurotransmitter receptors resulting in opening of voltage-dependent sodium channels located at the postsynaptic muscle membrane [23]. The inflow of sodium ions affects the local extracellular potential at the junction. It is difficult to test the sodium current along the synaptic cleft. Therefore, we investigated voltage-gated insect sodium channels expressed in Xenopus oocytes. However, more studies need to be done to examine whether HA induced hyperpolarizing shift of the voltage dependence of fast inactivation of sodium channels were correlated with the decay rate delayed EJPs and the increased mEJP frequency.

Electrophysiological measurements showed that HA delayed the decay rate of EJPs compared with the control. In terms of normal evoked EJPs recording, Peled et al. [28] reported that the amplitude of evoked EJP dropped to $0.93 \pm 0.07$ of the initial amplitude during low-frequency nerve stimulation over $20 \mathrm{~min}$. This finding was consistent with our result, at the same time with a corresponding drop to $0.914 \pm 0.057$ of the initial amplitude. Based on our recording in the control, the tendency of evoked EJP drop was time dependent. By contrast, HA produced only a small, insignificant decrease in evoked EJPs amplitude, and maintained the evoked EJPs in response to sustained low-frequency stimulation. This influence of post-synaptic responses evoked by motor-nerve stimulation produced by HA could promote the stability of pre- to post-synaptic transmission.

In our recordings, mEJPs showed a shift in distribution toward lower values and a decrease in frequency with time in the control. Similar results have been obtained by Peled et al. [28]. In the presence of $\mathrm{HA}$, although the average of $\mathrm{mEJP}$ amplitude was insignificantly changed, the distribution of mEJP amplitude showed a shift toward lower values and then toward relatively higher values. Compared with the control, HA interestingly produced a significant increase in frequency with time. Thus, HA may increase spontaneous miniature release or alter pre-synaptic transmission. The phenomena could result from weakened regulation of synaptic vesicle exocytosis. Rees [29] observed increased mEPSP rate and multiquantal mEPSPs after treatment of cockroach nerves with metabolic inhibitors, and these effects were correlated with the clumping of synaptic vesicles and changes in the appearance of mitochondria in the pre-synaptic terminals. Increased mEPSP rate, 
multiquanta1 mEPSPs, and clumping of synaptic vesicles are all believed to be due to increased levels of intraterminal $\mathrm{Ca}^{2+}$. When $\mathrm{Ca}^{2+}$ ions bound to vesicle membranes, they decreased the negative surface charge and allowed the vesicles to adhere onto one another and onto the pre-synaptic membrane, thereby, facilitating release from the cell [29]. Salgado et al. [30] also found that deltamethrin-induced depolarization of nerve terminals increase the rate of mEJPs in housefly, and $\left[\mathrm{Ca}^{2+}\right]_{i}$ changes may be the basis for the large mEJPs produced and the rate increased by the pyrethroid. In agreement with Rees and Salgado et al., we proposed that HA may increase the levels of intraterminal $\mathrm{Ca}^{2+}$, contributing to increased $\mathrm{mEJP}$ release rate and multiquantal mEJPs. Therefore, further investigation of $\left[\mathrm{Ca}^{2+}\right]_{i}$ changes of in neuron cells is necessary to validate our prediction.

Our results also showed that HA altered the voltage dependence of inactivation of insect sodium channels expressed in Xenopus oocytes. HA produced a significant hyperpolarizing shift in the voltage dependence of inactivation of insect sodium channels. This finding suggested that fast inactivation developed at a more hyperpolarizing potential by HA promoting fast inactivation. Fast inactivation is known to be a highly important feature of sodium channel kinetics as it helped to repolarize the excitable membrane during an action potential "process being the repolarizing force". In terms of modulation of sodium channel inactivation by well-known toxins, various toxins, and other chemical agents slow or even abolish inactivation [31]. Pyrethroids shift the relation between activation and membrane potential in the direction of hyperpolarization and cause a similar shift of inactivation [32]. Many drugs including local anesthetics (LA) shift the voltage dependence of fast inactivation in the hyperpolarizing direction. Spiradoline, an arylbenzacetamide antiarrhythmic drug, which also produced a hyperpolarizing shift in the voltage-dependence of sodium channel inactivation. According to the Modulated Receptor Hypothesis (MRH), such a shift can be attributed to a higher affinity of the drug for the inactive state of the channel. It suggests that most clinically useful LA and antiarrhythmic drugs have a low affinity for the resting state of the sodium channel. Selective, high-affinity binding of the drug for the inactive state of the channel imparts specificity of blockade to abnormally-firing sodium channels, without inhibiting normal neuronal and cardiac sodium channel function [33]. Therefore, like LA, HA may have high-affinity binding for the inactive state of the sodium channel. In addition, dietary polyunsaturated fatty acids (PUFAs), particularly, $n-3$ class as contained in fish oil, are antiarrhythmic agents. They exerted their effect on cardiac $\left(\mathrm{Na}_{\mathrm{v}} 1.5\right) \mathrm{Na}^{+}$channels by reducing $\mathrm{I}_{\mathrm{Na}}$ and shifting the steady-state inactivation curve in the hyperpolarizing direction [34]. Pyrethroids and PUFAs significantly shifting the steady-state inactivation to more hyperpolarized direction may be similar to HA, but HA did not alter sodium current amplitudes and the activation kinetics of sodium channels. Further investigation on sodium channel inactivation will be conducted in the future.

\section{Materials and Methods}

\subsection{Compounds}

Haedoxan A (HA; technical grade, $\geqslant 98 \%$ ) was provided by the Institute of Pesticide Science, Northwest A \& F University (NWAFU, Yangling, Shaanxi, China). The structure of haedoxan A was elucidated as 1-hydroxy-2-[(2,6-dimethoxy-3,4-methylenedioxyphenyl)oxy]-6-[6'-methoxy-2'-methoxymethyl-3' (3,4-methylenedioxy) phenyl]-2', $3^{\prime}$-dihydro-1', $4^{\prime}$-benzodioxin-7'-yl]-3,7-dioxabicyclo[3.3.0]octane (Figure 4) [5]. HA was dissolved in dimethyl sulfoxide (DMSO) to prepare a stock solution of $10^{-2} \mathrm{M}^{2}$

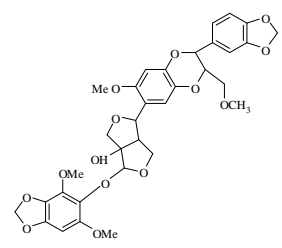

Figure 4. Structure of haedoxan A. 


\subsection{Insects}

A Drosophila stock $w^{1118}$ was reared on standard cornmeal food at $25^{\circ} \mathrm{C}$. Third-instar larvae were selected with either left the food ("wandering" stage) or remained in the food but had reached the prominent size characteristic of wandering third-instar larvae.

\subsection{Measurement of Synaptic Activity by Using Current Clamp}

Drosophila larvae were dissected, and the nerves projecting from the ventral ganglion were cut. Intracellular recordings were made ventral longitudinally from muscle 6 in segments A3 and A4 of wandering third-instar larvae as previously described [35,36]. Sharp voltage-recording glass microelectrodes (20-30 M $\Omega$ ) (Sutter Instrument, Novato, CA, USA), made of borosilicate glass (outer diameter, $1.2 \mathrm{~mm}$ ), and were filled with $3 \mathrm{M} \mathrm{KCl}$. The signal was acquired with an Axonclamp 900 A amplifier (Axon Instruments, Foster City, CA, USA), digitized with a Digidata 1440 A interface (Axon Instruments), and stored on a personal computer using pClamp 10.2 (Axon Instruments). Recordings were performed in HL3 (hemolymph-like 3) physiological solution, which produced an ionic composition and osmolarity most similar to that of Drosophila hemolymph [35] that contained: $70 \mathrm{mM} \mathrm{NaCl}, 5 \mathrm{mM} \mathrm{KCl}, 1.5 \mathrm{mM} \mathrm{CaCl}_{2}, 20 \mathrm{mM} \mathrm{MgCl}_{2}, 10 \mathrm{mM} \mathrm{NaHCO}_{3}, 5 \mathrm{mM}$ trehalose, $115 \mathrm{mM}$ sucrose, and $5 \mathrm{mM}$ HEPES (pH was adjusted to 7.2). Only cells with a resting potential between -60 and $-80 \mathrm{mV}$ were included in the analysis.

Spontaneously-occurring mEJPs and evoked EJPs were recorded using sharp voltage recording. mEJPs and EJPs provided a profile of spontaneous and nerve-evoked release at the whole-cell level. Evoked EJPs were elicited by stimulating the segmental nerve at $0.1 \mathrm{~Hz}$ [37] with a glass-suction electrode that had been heat-polished to $10 \mu \mathrm{m}$ inside diameter. Stimulating pulses were generated by JL-C4 V2a stimulator (Jialong Instruments, Shanghai, China). The amplitude of the pulse was set to about $5 \mathrm{~V}$, which resulted in the stable recruitment of both innervating motoneurons. This result corresponded to 1.5 times the amplitude needed to recruit both motoneurons innervating muscle 6 [38].

The frequency of mEJPs was determined by counting the number of events for a period of $1 \mathrm{~min}$. For each individual experiment, the frequency of mEJPs was measured three times over per minute intervals. The average of three measures was taken to represent the mEJP frequency for that particular experiment. For each $\mathrm{mEJP}$ and EJP average, $60 \mathrm{~s}$ of mEJP recording and 10 sequential EJPs were used for subsequent analysis.

The HA stock solution $\left(10^{-2} \mathrm{M}\right)$ was diluted in HL3 saline to prepare the test solution $\left(10^{-5} \mathrm{M}\right)$ at the beginning of each experiment. When the recording electrode was impaled into muscle cell and resting membrane potential was stable for $5 \mathrm{~min}, 1 \mathrm{~mL}$ of bath saline was drawn off from bath chamber whose bath saline volume was $4 \mathrm{~mL}$, and the same volume of HL3 saline containing HA of interest was added to the chamber for recording. The final bath concentration of HA was $2.5 \times 10^{-6} \mathrm{M}$ at $\mathrm{DMSO}<0.1 \%$. Control experiments were conducted with DMSO only. Recordings were conducted as described by Peled et al. [28] with minor modifications. After adding HA to bath saline, a 3 min waiting period was useful for eliminating artifacts caused by Vm drift in response to fast HA application. Therefore, the recording result at 3 min after testing application was deemed the initial or baseline value for further analyses.

\subsection{Expression of Insect Sodium Channels in Xenopus Laevis Oocytes and Electrophysiological Recording}

The procedures for the functional expression and characterization of sodium channels from Blattella germanica $\left(\mathrm{BgNa}_{\mathrm{v}}\right)$, Drosophila melanogaster $\left(\mathrm{DmNa}_{\mathrm{v}}\right)$, and Aedes aegypti $\left(\mathrm{AaNa}_{\mathrm{v}}\right)$ in Xenopus oocytes were identical to those previously reported [39-41]. The procedures for oocyte preparation and cRNA injection were identical to those described previously [42]. For the robust expression of cockroach $\mathrm{BgNa}_{\mathrm{v}}$ 1-1a sodium channel, Drosophila $\mathrm{DmNa}_{\mathrm{v}} 22$ channel, and Aedes aegypti $\mathrm{AaNa}_{\mathrm{v}} 1-1$ channel, their cRNAs were co-injected into oocytes with cRNA encoding the Drosophila melanogaster tipE auxiliary subunit (1:1 ratio), which enhanced the expression of insect sodium channels in oocytes. 
Methods for electrophysiological recording and data analyses were identical to those described previously [42]. All experiments were performed at room temperature. Sodium currents were measured with an OC725C oocyte clamp (Warner Instruments, Hamden, CT, USA) and a Digidata 1440A interface (Axon Instruments). pCLAMP 10.2 software (Axon Instruments) was used for data acquisition and analysis.

The HA stock solution $\left(10^{-2} \mathrm{M}\right.$ ) was diluted in ND96 (consisting of $96 \mathrm{mM} \mathrm{NaCl}, 2.0 \mathrm{mM} \mathrm{KCl}$, $1.0 \mathrm{mM} \mathrm{MgCl} 2,1.8 \mathrm{mM} \mathrm{CaCl}$, and $10 \mathrm{mM}$ HEPES, $\mathrm{pH}$ adjusted to 7.5 with $\mathrm{NaOH}$ ) recording solution as the test solution $\left(10^{-5} \mathrm{M}\right)$ just before experiments. DMSO concentration in the final solution was $<0.5 \%$, which had no effect on the function of sodium channels in these experiments. The method for application of chemicals in the recording system was identical to that described previously [43]. The effects of HA were measured $10 \mathrm{~min}$ after toxin application.

The peak current was measured by a $20 \mathrm{~ms}$ test pulse to $-10 \mathrm{mV}$ from a holding potential of $-120 \mathrm{mV}$ before and after HA application. The voltage dependence of sodium channel conductance (G) was calculated by measuring the peak current at test potentials ranging from -80 to $+65 \mathrm{mV}$ in $5-\mathrm{mV}$ increments and divided by $(\mathrm{V}-\mathrm{Vrev})$, where $\mathrm{V}$ is the test potential and Vrev is the reversal potential for sodium ion. Peak conductance values were normalized to the maximal peak conductance (Gmax) and fitted with a two-state Boltzmann equation of the form G/Gmax $=\left[1+\exp \left(V-V_{1 / 2}\right) / k\right]-1$, in which $V$ is the potential of the voltage pulse, $V_{1 / 2}$ is the half-maximal voltage for activation, and $\mathrm{k}$ is the slope factor.

The voltage dependence of fast inactivation was determined using $200 \mathrm{~ms}$ inactivating prepulses from a holding potential of -120 to $40 \mathrm{mV}$ in $5 \mathrm{mV}$ increments, followed by test pulses to $-10 \mathrm{mV}$ for $20 \mathrm{~ms}$. The peak current amplitude during test depolarization was normalized to the maximum current amplitude and plotted as a function of the prepulse potential. Data were fitted with a two-state Boltzmann equation of the form $I / I_{\max }=\left[1+\left(\exp \left(V-V_{1 / 2}\right) / k\right)\right]^{-1}$, in which $I_{\max }$ is the maximal current evoked, $V$ is the potential of the voltage pulse, $V_{1 / 2}$ is the half-maximal voltage for inactivation, and $k$ is the slope factor.

\subsection{Data Collection and Analysis}

Data were statistically analyzed using SPSS software (version 12.0, SPSS Inc., Chicago, IL, USA, 2003) and Microcal Origin 8.6 (Origin Lab Corp, Northampton, MA, USA, 2013). Data are presented as the mean \pm S.D. Statistical significance was determined by Student's $t$-test and Scheffe's post hoc analysis, and significant values were set at $p<0.05$ or as indicated in the table and figure legends.

\section{Conclusions}

HA could alter the response of pre- to post-synaptic transmission by delaying the decay rate of EJPs and by increasing the frequency of mEJPs at the Drosophila NMJ. A significant hyperpolarizing shift in the voltage-dependence of inactivation of insect sodium channels was produced. HA exerted toxic effects by disrupting the function of both conduction of action potentials and synaptic transmission. Our work provided the basis for developing a novel natural botanical pesticide based on HA as a major insecticidal active ingredient.

Acknowledgments: This study was partly sponsored by the grant of the National Natural Science Foundation of China $(31171868,31371958,31300548)$, the National Key Basic Research Program (973 Program, 2010CB126100) from Science and Technology, Ministry of China) and the National Institutes of Health of the United States (GM 080255).

Author Contributions: The experiments were conceived and designed by Z.H. and W.W. The experiments were performed by Z.H., Y.D., and X.X. Data was analyzed by Z.H., Y.D. and K.D. The paper was written by Z.H., Y.D. and K.D.

Conflicts of Interest: The authors declare no conflict of interest. 


\section{References}

1. Huang, T.; Ting, Z.; Zhao, S. Modern Compendium of Materia Medica; China Medical Science Press: Beijing, China, 2001; p. 934.

2. Lee, S.; Min, B.; Kho, Y. Brine shrimp lethality of the compounds from Phryma leptostachya L. Arch. Pharm. Res. 2002, 25, 652-654. [CrossRef] [PubMed]

3. Taniguchi, E.; Oshima, Y. Phrymarolin-I, a novel lignan from Phryma leptostachya L. Agric. Biol. Chem. 1972, 36, 1018-1025. [CrossRef]

4. Taniguchi, E.; Oshima, Y. Structure of phrymarolin-II. Agric. Biol. Chem. 1972, 36, 1489-1496. [CrossRef]

5. Taniguchi, E.; Imamura, K.; Ishibashi, F.; Matsui, T.; Nishio, A. Structure of the novel insecticidal sesquilignan, haedoxan A. Agric. Biol. Chem. 1989, 53, 631-643. [CrossRef]

6. Ishibashi, F.; Taniguchi, E. Syntheses of $( \pm)$-haedoxan A, D, E and their Stereoisomers. Agric. Biol. Chem. 1989, 53, 1565-1573. [CrossRef]

7. Ishibashi, F.; Taniguchi, E. Synthesis and absolute configuration of the insecticidal sesquilignan (+)-Haedoxan A. Phytochemistry 1998, 49, 613-622. [CrossRef]

8. Ishibashi, F.; Taniguchi, E. Syntheses of ( \pm )-phrymarolin II and its stereoisomers. Agric. Biol. Chem. 1986, 50, 3119-3122. [CrossRef]

9. Ishibashi, F.; Taniguchi, E. Synthesis and absolute configuration of the acetalic lignan (+)-phrymarolin I. Bull. Chem. Soc. Jpn. 1988, 61, 4361-4366. [CrossRef]

10. Yamauchi, S.; Taniguchi, E. Synthesis and insecticidal activity of lignan analogs (I). Agric. Biol. Chem. 1991, 55, 3075-3084. [CrossRef]

11. Yamauchi, S.; Taniguchi, E. Synthesis and insecticidal activity of lignan analogs (II). Agric. Biol. Chem. 1992, 56, 412-417. [CrossRef]

12. Okazaki, M.; Ishibashi, F.; Shutout, Y.; Taniguchi, E. Total synthesis of (+)-phrymarolin I from (+)-malic acid. Biosci. Biotechnol. Biochem. 1997, 61, 660-663. [CrossRef]

13. Park, I.; Shin, S.; Kim, C.; Lee, H.; Choi, W.; Ahn, Y. Larvicidal activity of lignans identified in Phryma leptostachya var. asiatica roots against three mosquito species. J. Agric. Food Chem. 2005, 53, 969-972. [CrossRef] [PubMed]

14. Seo, S.; Park, I. Larvicidal activity of medicinal plant extracts and lignan identified in Phryma leptostachya var. asiatica roots against housefly (Musca domestica L.). Parasitol. Res. 2012, 110, 1849-1853. [CrossRef] [PubMed]

15. Xiao, X.; Hu, Z.; Shi, B.; Wei, S.; Wu, W. Larvicidal activity of lignans from Phryma leptostachya L. against Culex pipiens pallens. Parasitol. Res. 2012, 110, 1079-1084. [CrossRef] [PubMed]

16. Xiao, X.; Hu, Z.; Ji, Z.; Shi, B.; Wei, S.; Wu, W. Isolation, structure identification and bioactivity of active ingredients from Phryma leptostachya. Chin. J. Pestic. Sci. 2012, 14, 583-586.

17. Xiao, X.; Ji, Z.; Zhang, J.; Shi, B.; Wei, S.; Wu, W. A new lignan from Phryma leptostachya L. Chem. Nat. Compd. 2013, 49, 21-23. [CrossRef]

18. Ozoe, Y; Hasegawa, H.; Mochida, K.; Satoh, H.; Iwabuchi, J.; Kurozumi, A.; Taniguchi, E. Sesquilignan haedoxans: Interaction with the GABAA receptor in rat brain. Biosci. Biotechnol. Biochem. 1994, 58, 760-761.

19. Collins, C.A.; DiAntonio, A. Synaptic development: Insights from Drosophila. Curr. Opin. Neurobiol. 2007, 17, 35-42. [CrossRef] [PubMed]

20. Krans, J.L.; Parfitt, K.D.; Gawera, K.D.; Rivlin, P.K.; Hoy, R.R. The resting membrane potential of Drosophila melanogaster larval muscle depends strongly on external calcium concentration. J. Insect Physiol. 2010, 56, 304-313. [CrossRef] [PubMed]

21. Ramirez, D.M.; Kavalali, E.T. Differential regulation of spontaneous and evoked neurotransmitter release at central synapses. Curr. Opin. Neurobiol. 2011, 21, 275-282. [CrossRef] [PubMed]

22. Choi, B.J.; Imlach, W.L.; Jiao, W.; Wolfram, V.; Wu, Y.; Grbic, M.; Cela, C.; Baines, R.; Nitabach, M.N.; McCabe, B.D. Miniature neurotransmission regulates Drosophila synaptic structural maturation. Neuron 2014, 82, 618-634. [CrossRef] [PubMed]

23. Mahmud, M.; Rahman, M.M.; Vassanelli, S. Na ${ }^{+}$Channels at postsynaptic muscle membrane affects synaptic transmission at neuromuscular junction: A simulation study. In Proceedings of the 34th Annual International Conference of the IEEE EMBS, San Diego, CA, USA, 28 August-1 September 2012; pp. 3616-3619.

24. Catterall, W.A. From ionic currents to molecular mechanisms: The structure and function of voltage-gated sodium channels. Neuron 2000, 26, 13-25. [CrossRef] 
25. Flucher, R.E.; Danielst, M.P. Distribution of $\mathrm{Na}^{+}$channels and Ankyrin in neuromuscular junctions is complementary to that of acetylcholine receptors and the $43 \mathrm{kd}$ Protein. Neuron 1989, 3, 163-175. [CrossRef]

26. Boudier, J.L.; le Treut, T.; Jover, E. Autoradiographic localization of voltage-dependent sodium channels on the mouse neuromuscular junction using 12SI-cy-scorpion toxin. II. Sodium channel distribution on postsynaptic membranes. J. Neurosci. 1992, 12, 454-466. [PubMed]

27. Lupa, M.T.; Krzemien, D.M.; Schaller, K.L.; Caldwell, J.H. Aggregation of sodium channels during development and maturation of the neuromuscular junction. J. Neurosci. 1993, 13, 1326-1336. [PubMed]

28. Peled, E.S.; Newman, Z.L.; Isacoff, E.Y. Evoked and spontaneous transmission favored by distinct sets of synapses. Curr. Biol. 2014, 24, 484-293. [CrossRef] [PubMed]

29. Rees, D. The effect of metabolic inhibitors on the cockroach nerve-muscle synapse. J. Exp. Biol. 1974, 61, 331-343. [PubMed]

30. Salgado, V.L.; Irving, S.N.; Miller, T.A. Depolarization of motor nerve terminals by pyrethroid in susceptible and $k d r$-resistant house flies. Pestic. Biochem. Physiol. 1983, 20, 100-114. [CrossRef]

31. Ulbricht, W. Sodium channel inactivation: molecular determinants and modulation. Physiol. Rev. 2005, 85, 1271-1301. [CrossRef] [PubMed]

32. Motomura, H.; Narahashi, T. Temperature dependence of pyrethroid modification of single sodium channels in rat hippocampal neurons. J. Membr. Biol. 2000, 177, 23-39. [CrossRef] [PubMed]

33. Pugsley, M.K.; Yu, E.J.; Goldin, A.L. Spiradoline, a kappa opioid receptor agonist, produces tonic- and use-dependent block of sodium channels expressed in Xenopus oocytes. Gen. Pharmacol. 2000, 34, 417-427. [CrossRef]

34. Xiao, Y.F.; Kem, Q.; Wang, S.Y.; Auktor, K.; Yang, Y.; Wang, G.K.; Morgan, J.P.; Leaf, A. Single point mutations affect fatty acid block of human myocardial sodium channel a subunit $\mathrm{Na}^{+}$channels. Proc. Natl. Acad. Sci. USA 2001, 98, 3606-3611. [CrossRef] [PubMed]

35. Stewart, B.A.; Atwood, H.L.; Renger, J.J.; Wang, J.; Wu, C.F. Improved stability of Drosophila larval neuromuscular preparations in haemolymph-like physiological solutions. J. Comp. Physiol. 1994, 175, 179-191. [CrossRef]

36. Stewart, B.A.; Schuster, C.M.; Goodman, C.S.; Atwood, H.L. Homeostasis of synaptic transmission in Drosophila with genetically altered nerve terminal morphology. J. Neurosci. 1996, 16, 3877-3886. [PubMed]

37. Stimson, D.T.; Estes, P.S.; Smith, M.; Kelly, L.E.; Ramaswami, M. A product of the Drosophila stoned locus regulates neurotransmitter release. J. Neurosci. 1998, 18, 9638-9649. [PubMed]

38. Ormerod, K.G.; Hadden, J.K.; Deady, L.D.; Mercier, A.J.; Krans, J.L. Action of octopamine and tyramine on muscles of Drosophila melanogaster larvae. J. Neurophysiol. 2013, 110, 1984-1996. [CrossRef] [PubMed]

39. Tan, J.; Liu, Z.; Nomura, Y.; Goldin, A.L.; Dong, K. Alternative splicing of an insect sodiumchannel gene generates pharmacologically distinct sodium channels. J. Neurosci. 2002, 22, 5300-5309. [PubMed]

40. Olson, R.O.; Liu, Z.; Nomura, Y.; Song, W.; Dong, K. Molecular and functional characterization of voltage-gated sodium channel variants from Drosophila melanogaster. Insect Biochem. Mol. Biol. 2008, 38, 604-610. [CrossRef] [PubMed]

41. Du, Y.; Nomuraa, Y.; Satar, G.; Hu, Z.; Nauen, R.; He, S.Y.; Zhorove, B.S.; Dong, K. Molecular evidence for dual pyrethroid-receptor sites on a mosquito sodium channel. Proc. Natl. Acad. Sci. USA 2013, 110, 11785-11790. [CrossRef] [PubMed]

42. Du, Y.; Nomura, Y.; Luo, N.; Liu, Z.; Lee, J.E.; Khambay, B.; Dong, K. Molecular determinants on the insect sodium channel for the specific action of type II pyrethroid insecticides. Toxicol. Appl. Pharmacol. 2009, 234, 266-272. [CrossRef] [PubMed]

43. Tan, J.; Liu, Z.; Wang, R.; Huang, Z.Y.; Chen, A.C.; Gurevitz, M.; Dong, K. Identification of amino acid residues in the insect sodium channel critical for pyrethroid binding. Mol. Pharmacol. 2005, 67, 513-522. [CrossRef] [PubMed]

(C) 2016 by the authors; licensee MDPI, Basel, Switzerland. This article is an open access article distributed under the terms and conditions of the Creative Commons by Attribution (CC-BY) license (http:/ / creativecommons.org/licenses/by/4.0/). 